\title{
BIM AND GIS: WHEN PARAMETRIC MODELING MEETS GEOSPATIAL DATA
}

\author{
L. Barazzetti, F. Banfi \\ Dept. of Architecture, Built environment and Construction engineering (ABC) \\ Politecnico di Milano, Piazza Leonardo da Vinci 32, Milan, Italy \\ (luigi.barazzetti, fabrizio.banfi)@polimi.it
}

Commission V, WG V/7

KEY WORDS: BIM, Geospatial Data, GIS, Infrastructure, Integration, Land Management, Parametric Modeling

\begin{abstract}
:
Geospatial data have a crucial role in several projects related to infrastructures and land management. GIS software are able to perform advanced geospatial analyses, but they lack several instruments and tools for parametric modelling typically available in BIM. At the same time, BIM software designed for buildings have limited tools to handle geospatial data. As things stand at the moment, BIM and GIS could appear as complementary solutions, notwithstanding research work is currently under development to ensure a better level of interoperability, especially at the scale of the building. On the other hand, the transition from the local (building) scale to the infrastructure (where geospatial data cannot be neglected) has already demonstrated that parametric modelling integrated with geoinformation is a powerful tool to simplify and speed up some phases of the design workflow. This paper reviews such mixed approaches with both simulated and real examples, demonstrating that integration is already a reality at specific scales, which are not dominated by "pure” GIS or BIM. The paper will also demonstrate that some traditional operations carried out with GIS software are also available in parametric modelling software for BIM, such as transformation between reference systems, DEM generation, feature extraction, and geospatial queries. A real case study is illustrated and discussed to show the advantage of a combined use of both technologies. BIM and GIS integration can generate greater usage of geospatial data in the AECOO (Architecture, Engineering, Construction, Owner and Operator) industry, as well as new solutions for parametric modelling with additional geoinformation.
\end{abstract}

\section{INTRODUCTION}

Geospatial information plays a fundamental role in planning at urban or regional scale. Geospatial data are usually handled with GIS engines, including both open-source and proprietary software. Modern sw deal with various data formats, variable scales, different reference systems, etc. They have specific tools for advanced analysis on raster and vector files, for instance for detecting and quantifying patterns, making predictions, running spatial queries and measurements.

In recent years, BIM has become very attractive in construction projects thanks to the organized workflow provided during the different stages of the project: program, design, construction, operation, and demolition. BIM is an organized 3D model of the building with database. Changes in the model are automatically reflected in the database, and vice versa.

Acronyms BIM (Building Information Modeling) and GIS (Geographic Information System) share the "I" of information. In fact, they have a database connected to a graphic representation of geometric entities, which could be points, lines and polygons for GIS or parametric objects (such as walls, windows, doors, ...) for BIM.

An important difference between BIM and GIS is the opportunity to represent different elements at a specific scale, using a different approach (Fig. 1). For this reason, BIM and GIS can be simultaneously exploited to solve related but different problems. An integrated approach in data processing requires preliminary knowledge of both technologies, moving the analysis (from and to) specific software packages. From this point of view, BIM and GIS can be used together as they are complementary. On the other hand, this does not mean that there is no direct integration. This means that there are different applications with different degrees of integration. It is not the author's intention to provide a detailed review. More details on integration between BIM and GIS can be found in Amirebrahimi et al. (2016), Baik et al. (2015), Borrmann et al. (2014), Del Giudice et al. (2015), El Meouche et al. (2013), Fan (2016), Kang and Hong (2015), Karan and Irizarry (2015), Liu et al. (2016), Yamamura et al. (2017), Vilgertshofer et al. (2017), Wang et al. (2014), and Zlatanova and Isikdag (2016).

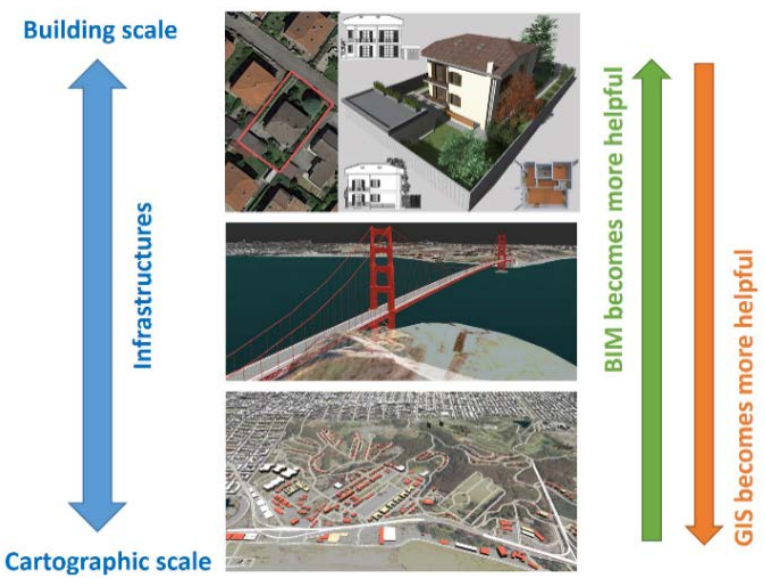

Figure 1. BIM and GIS can be intended as complementary solutions in several projects. Specific tools are available to solve for different aspects of practical applications.

In the case of infrastructures, the relationship between geospatial data and construction data becomes very effective. According to Cheng et al. (2016), the infrastructure scale includes the following categories: 
- transportation infrastructure - roads, railways, bridges, tunnels and mass transit hubs (such as airports, ports \& harbours);

- energy infrastructure: - power generation plants (nuclear, wind, tidal etc.), oil \& gas (storage/distribution terminals, refineries, wells etc.) and mining;

- utility infrastructure - networks/pipelines for the delivery and removal of electricity, gas, water \& sewage;

- recreational facilities infrastructure, such as parks, stadiums, etc.;

- environmental infrastructures, such as structures for managing flood and coastal defence such as dams, levees, weirs or embankments.

A review of BIM for infrastructures is reported in Bradley et al. (2016), Dongmo-Engeland and Merschbrock (2017), Kim et al. (2016), Minagawa and Kusajanaci (2015), Shou et al. (2015). Applications, examples and case studies were described by Chong et al. (2016), Di Giulio et al. (2017), Ehrbar (2016), Fanning et al. (2015), Kim et al. (2015a,b), Konig et al. (2017), Kortstee and van der Geest (2017), Omoregie and Turnbull (2016).

BIM for infrastructure is a powerful tool not only during the design and construction phase, but also for managing the infrastructure in a more sustainable and efficient way. Infrastructure projects requires expertise in geospatial data and engineering design. The typical parametric modelling approach of BIM technology cannot neglect georeferenced information for infrastructure projects. BIM elements have to interact with spatial data in raster and vector formats so that the BIM will be automatically georeferenced and connected to the different data sources. A change in a particular element will be automatically reflected in data sources or other objects that have a direct correlation with it.

\section{PARAMETRIC MODELING WITH GEOSPATIAL DATASETS}

This section describes a very basic example that shows how infrastructure design can be carried out using geospatial data and parametric modelling tools. The idea is to highlight how geospatial data have an essential role also in parametric modelling, notwithstanding the reported case study are quite simplified.

According to (Eastman et al., 2011, chapter 1), parametric objects:

- contain geometric information and associated data and rules;

- $\quad$ have non-redundant geometry, which allows for no inconsistencies;

- have parametric rules that automatically modify associated geometries when inserted into a building model or when changes are made to associated objects;

- $\quad$ can be defined at different levels of aggregation, and;

- have the ability to link to or receive, broadcast, or export sets of attributes such as structural materials, acoustic data, energy data, cost, etc., to other applications and models.

The first example of this section shows results at the level of the building, in which a (simplified) model can be generated assembling BIM objects. In the second example (road design), a new (simplified) road is created using parametric modelling tools that have to interact with geospatial data.

\subsection{The tradition BIM approach: parametric modelling of a new building}

BIM software are mainly designed to represent the building and its elements. The typical workflow for the generation of a new (as-designed) BIM requires the assembly of predefined objects already subdivided into categories (walls, columns, floors, roofs, windows, doors, ceilings, ramps, etc.). Objects are placed in levels (e.g. foundation, floor, ceiling, roof, etc.), which provide a sort of reference system. Levels can be intended as horizontal planes for the different storeys of the construction.

GIS software cannot represent the complexity of the building with this level of detail, especially interiors or buildings. For instance, a basic external wall can be easily placed after choosing between the type of wall and its width. The wall is made up of different layers (finish, air layer, membrane, substrate, structures, ...) with different materials (brick, air, air infiltration barrier, plywood, metal stud, ...) and thicknesses. Analytical properties are also provided, such as the heat transfer coefficient thermal mass and roughness.

Similar considerations are still valid for other basic elements, such as doors and windows, which can be included in the model after choosing the type and its dimension (some of the parameters are functions, materials, dimensions, still height, head height, frame type, etc.). They can be included only in walls (also in roofs and skylights in the case of windows) with a cut automatically performed by the software.

The design phase continues with the progressive accommodation of other elements. The building (Figure 2) is therefore designed from an architectural point of view (objects like stairs, railings, ramps, etc.) along with structural considerations (columns, trusses, braces, beams, foundations, etc.).

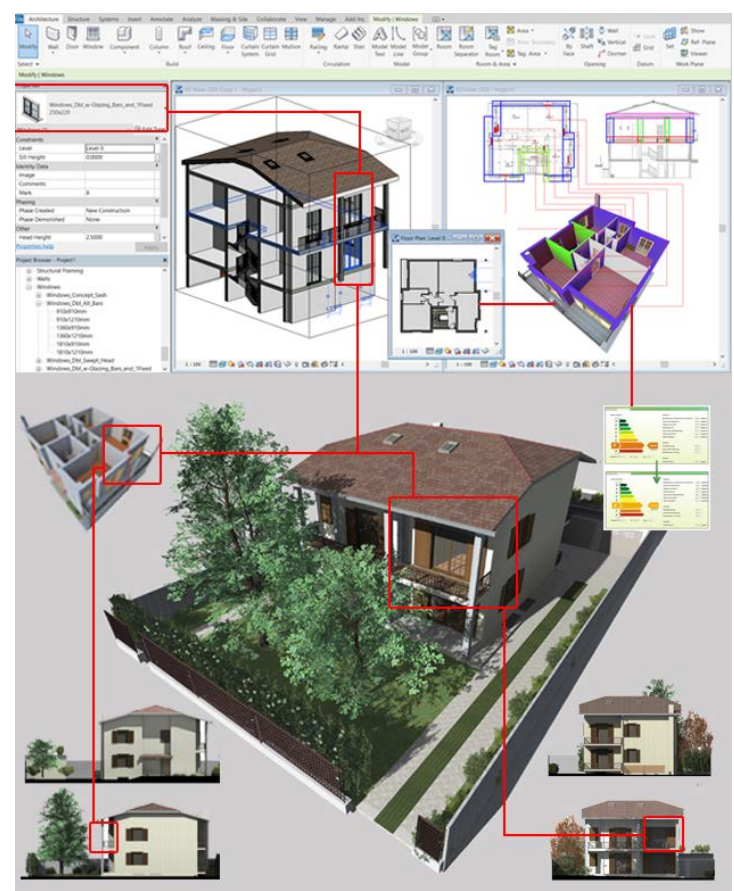

Figure 2. As-built BIM of a (simplified) building obtained with the parametric modelling logic of BIM software.

Operations are carried out directly in a 3D environment and 2D views (plans, sections, elevations) are automatically created by the software (Fig. 2, bottom).

Systems (pipes, electrical equipment, air terminals, etc.) are also standard BIM objects. However, a BIM project is not only a 3D 
assembly of elements. BIM objects are added considering both geometric and semantics aspects, transforming the designed house into a dynamic database where objects are interconnected by their functional characteristics. This consistent representation of the construction is a powerful approach to building design where conflicts between objects (e.g. self-intersections) can be automatically identified, reports and drawings (plans, sections, etc.) are generated from the 3D model in a fully automated way, and advanced simulation can be run.

\subsection{BIM for infrastructure: parametric modelling of a new road with integrated geospatial data}

The previous example highlights that BIM technology is very helpful in representing the building at the local scale. On the other hand, GIS becomes more powerful for data analysis at the cartographic scale. The idea is to move the BIM logic from buildings to infrastructures, which require new objects that can interact with geospatial datasets. At the same time, objects have to be manipulated and personalized with the traditional logic of parametric modeling.

In the previous example, no geographic reference system was required and the (building) project had a local Cartesian system where objects are progressively added in the different levels (such as ground floor, first floor, etc.). Infrastructures are different. They require a geographic reference system. For instance, a common choice is the UTM projection, but another solution could be the direct use of geographic coordinates (latitude and longitude). Local reference systems can also be used, but this is not a convenient choice when multiple data sources are available. Indeed, geospatial data have a reference system. Tools for automatic change of reference system could be an advantage but also a source of errors, especially when approximated transformation are implemented (e.g. between national and international reference systems, where rigours solution are (sometimes) substituted by approximated methods. As the algorithms used to project different datasets in different reference systems are not known (the transformation becomes a sort of black box), we prefer to operate with data already georeferenced in a single reference system (UTM WGS84 ETRF 89).

Figure 3 (left) shows the geospatial data used for the preliminary design project of a new road. Such data include shapefiles of the road network and the river, building layers, a digital terrain model and an orthophoto. The project consists in the connection of the small village with the main road on the other side of the river.
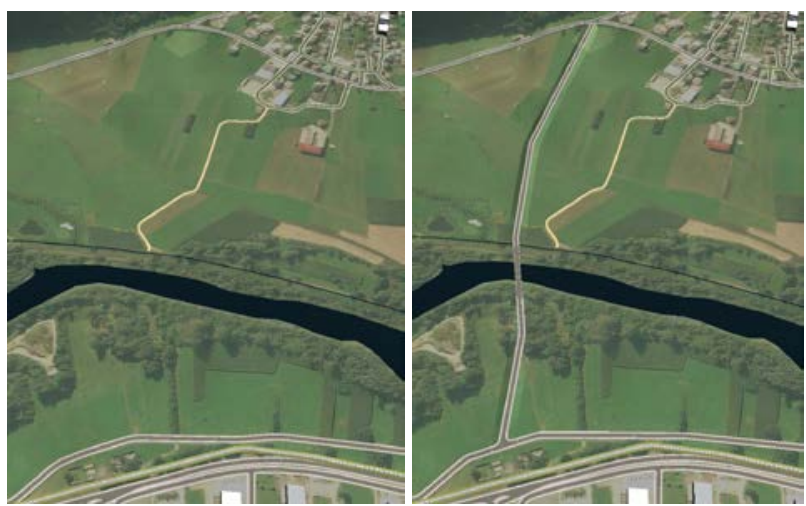

Figure 3. The area with (right) and without (left) the new road designed via parametric modelling.
The new road was created with an automated procedure, choosing the type of road from a predefined database and tracing its 3D profile directly on the digital terrain model.

Figure 3 (right) shows the new road and its curves, which have a small radius. A simple change of the radius allows the software to remodel the road with a smoother trajectory.

The new road is an object able to interact with existing roads. Indeed, intersections create themselves whenever two or more roads are in close proximity. Then, intersections can be interactively modified, changing the location of stop signs or adding a single lane roundabout, as shown in Figure 4.

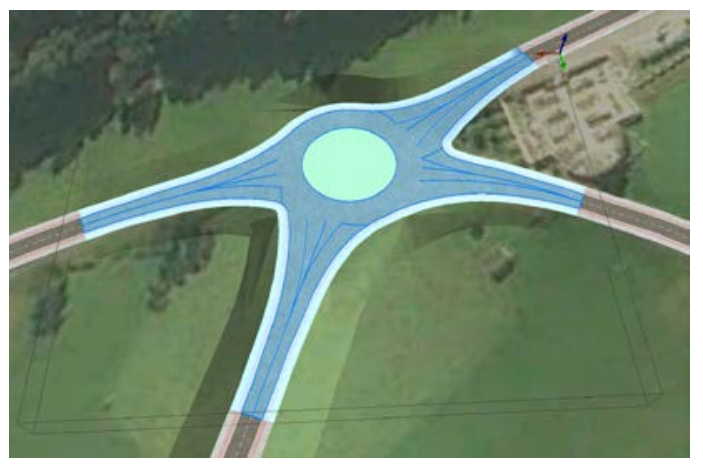

Figure 4. A roundabout is automatically added by changing the type of intersection where two or more roads are in close proximity.

The road is also able to interact with the river. Indeed, here a bridge is automatically added, notwithstanding the default choice follows the elevation values in the DTM (Figure 6, top). The bridge is then manually modified by changing the number of columns, setting a predefined length, and modifying the vertical profile of the road. Such operations can be carried with the parametric modelling tools, which allows a graphic editing of the 3D model.

The final result is shown in Figure 5 (bottom). It is important to mention that additional products can be derived from this solution. Parametric modelling tools able to interact with geospatial data are a powerful instrument to obtain a very quick response in the case of modifications.

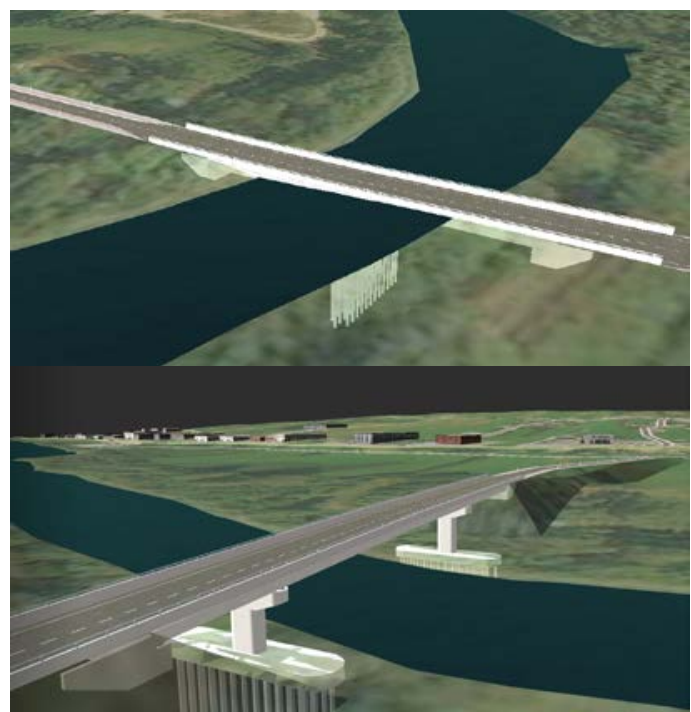

Figure 5. The bridge in the first step of parametric modelling (top) and the final solution after some manual corrections (bottom). 


\section{TYPES OF GEOSPATIAL DATA USEFUL IN BIM FOR INFRASTRCTURES}

Different geospatial data in different formats have to be collected for a project at the level of landscape. Some input sources do not require additional processing and can be directly processed by the user. In some cases, additional information must be pre-processed to make it readable by parametric modelling engines.

The description here presented is based on the tools provided by Autodesk Infraworks, which is specifically designed for BIM and infrastructures. A project can start from a digital terrain model that defines the shape of the ground. Typical representations for terrain data are raster (e.g. TIFF *.tif, ArcMap *.asc, DEM *.dem, Erdas file format *.img, etc.), triangulated irregular networks (TIN) or contour lines (e.g. CAD). Then, orthophotos generated from aerial or satellite images can be projected on the digital terrain model, so that the user can have a 3D textured visualization.

A remarkable advantage is the simple interface of the software, which is a $3 \mathrm{D}$ environment with the opportunity to have traditional visualizations (2D) along predefined planes (top, bottom, right, etc.). This is a difference between GIS software were visualization is usually $2 \mathrm{D}$, notwithstanding $3 \mathrm{D}$ visualization tools are also available in 3D GIS.

In the case of BIM, the user works in a 3D environment right from the beginning of data processing, and 2D visualization is just a result of operations carried out in 3D. The opportunity to connect georeferenced images is also a very attractive field of future work for a more integrated approach between BIM, photogrammetry, airborne laser scanning, and remote sensing. Vector files (such as shapefiles or CAD files) represent different categories of objects with points, lines, and polygons. For instance, roads, railways or rivers can be represented by lines. On the other hand, additional data are required to make existing vector layers useful in a BIM engine. The user has to specify the type of object among a set of predefined elements. After assigning the correct type, the software can use the instruments of parametric modelling to assist the user for further operations. An example is the intersection of two roads, which can be turned into a roundabout if software knows that those two lines are roads (and not rivers).

It is not the author's intention to provide a detailed explanation of the different kinds of objects that can be handled by BIM sw for infrastructures. The aim is to provide an overall view on the primary role reached by geospatial information in this kind of applications.

The growing interest in this field is also confirmed by the development of tools able to provide a simplified access to geospatial datasets. Indeed, running this kind of projects will always require geospatial datasets. The expert user of GIS technology knows how to access existing data repositories, including data sources not available online. However, Infraworks has the opportunity to retrieve geospatial data in a fully automated way from existing repositories, such as OpenStreetMap's buildings, highways, and railways, or orthophotos from BingMaps, and digital terrain models (e.g. USGS or Aster datasets). Geospatial information is also available for water bodies, such as lakes and rivers. A userfriendly interface (Figure 6) allows the user to identify the area of interest, for which a new project will be generated. The example shows the city of Lecco (in Italy), which is the case study illustrated in next section.

Some images of the model generated from the available data sources are shown in Figure 7. The objects are buildings, roads, railways, rivers, and lakes. Objects were directly related to terrain, so that they are forced to coincide with the digital terrain model. Most buildings have an approximated height and the roof is modeled with a basic flat surface. In some cases, complex roofs are available in the model. A simple inspection of the real ones revealed that the shape is not correct. This is a limitation of such databases where information is not always accurate and detailed.

Other kind of data, such as 3D models or BIM can be imported. Additional repositories (such as Oracle, WFS, PostGreSQL, ...) can also be connected. CityGML is no longer a supported source but files can be converted to IMX and then imported.

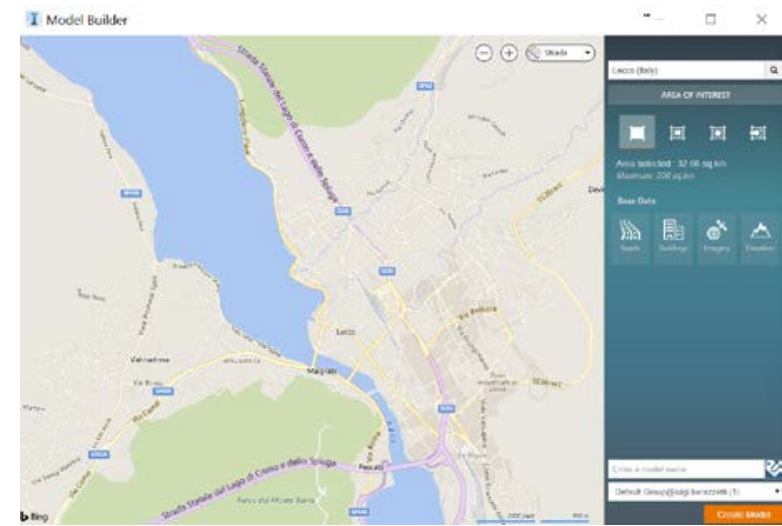

Figure 6. The graphical interface used to automatically retrieve geospatial data for the Lecco project (see next section).
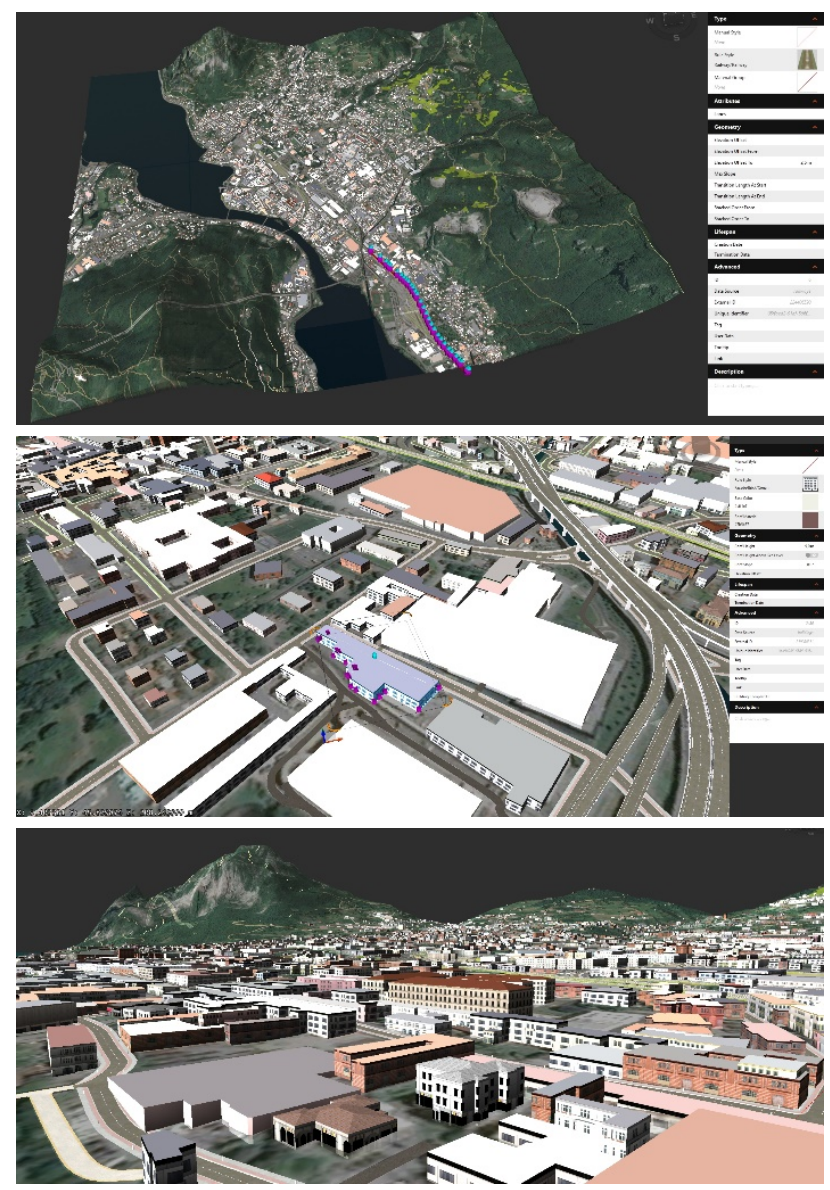

Figure 7. Some images of the geospatial data retrieved and imported in a BIM environment for further processing. 
Finally, point clouds can be imported and processed to digitize existing infrastructures. Dense point clouds generated from both aerial photogrammetry or LiDAR provide valuable information about the actual conditions of the area. Manual work is necessary to identify the different elements and turn them into parametric object. Automation is available for some geometric operations such as the generation of meshes or digital surface models (GRID).

\section{CASE STUDY}

The proposed case study is a bridge in the city of Lecco. Different experts (engineers, architects, etc.) contributed to define the class of the bridge, which is directly related to the load-carrying capacity. The problem can be described as follows: how many lanes can we safely utilize? Figure 8 shows the bridge before (2 lanes) and after the work (a single lane). The choice to reduce the number of vehicles on the bridge had an impact on traffic, requiring an analysis of a wider area to understand the effect of such decision at the district scale.
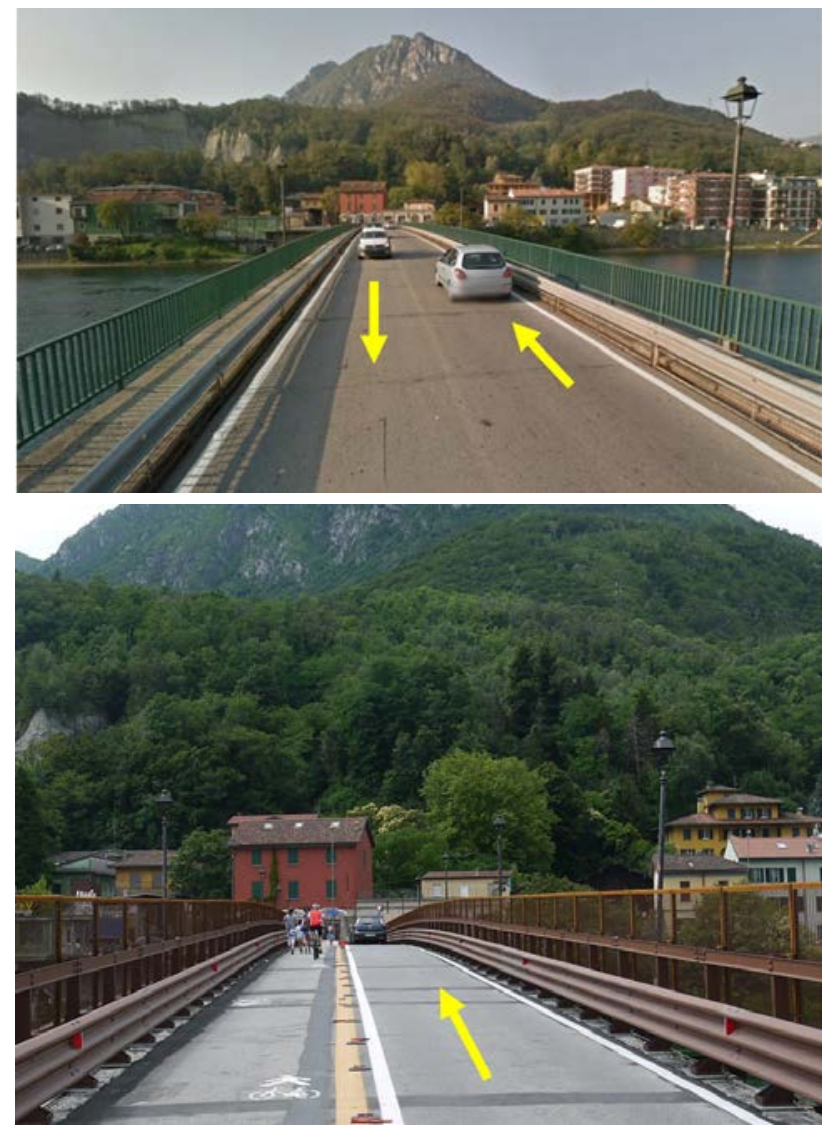

Figure 8. The bridge before and after the intervention: from two (top) to a single lane for cars (bottom), with a new pedestrian lane.

The work on the bridge is a multi-scale problem, which started from the acquisition of in-situ data for a detailed geometric survey of the infrastructure. In this phase, images and laser scans were processed to generate a detailed BIM at the scale 1:50. Figure 9 shows some images of the final model and some input data, which were useful for different analysis performed by the different specialists involved in the project (such as geotechnical analysis, structural simulation, mapping of materials and degradation effects, sonic inspections, georadar, etc).

It is not the author's intention to provide more details about this part of the work, which is described in Barazzetti et al. (2017) and Banfi et al. (2017). This paper starts with a change of the scale, moving from 1:50 to a wider area to simulate traffic flows. The idea is to verify what kind of information of the local survey can be reused in the traffic simulation, integrating new geospatial data such as the road network.

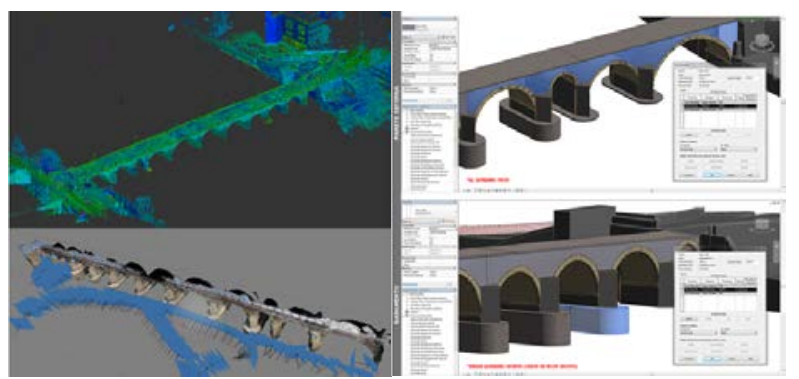

Figure 9. Images and laser scans acquired for the generation of the generation of a BIM at the scale 1:50.

The first consideration is the need of georeferenced products. Therefore some points of the bridge were measured via GPS. Then, the BIM was georeferenced in the system UTM WGS84 ETRF89, so that it can be analyzed along with the different geospatial data used for the traffic simulation, which were:

- $\quad$ Digital terrain model (raster);

- $\quad$ Aerial orthophoto (raster);

- Road network (vector);

- Network of other infrastructures, such as railways (vector);

- Water bodies, such as the lake and rivers (vector);

- Buildings (vector).

Such layers have a worse geometric resolution, which is the traditional cartographic scale 1:1000. For instance, most buildings are represented with simple boxes. The BIM of the bridge has instead a much higher resolution, in which even the different ashlars were modelled.

Buildings are necessary for a detailed analysis to understand visibility problem, such as occlusions, which have an impact on speed and time spent at intersections.

A doubt arises: can we use the detailed BIM of the bridge to simulate traffic conditions? It is the author's opinion that such detailed model has too many details for a traffic simulation. A careful revision and simplification would be needed to provide a model usable for this kind of analysis. This means that a very detailed model readapted for all kind of analyses is not a useful approach, because it requires significant extra work.

In the case of a (new) bridge generated in Infraworks, the bridge is built parametrically and is able to interact with other objects such as roads and water bodies. The BIM generated in Revit was not developed to be used for the traffic simulation, but for other analyses, more oriented to its stability. If the detailed BIM was extremely useful for the work presented in Barazzetti et al. (2017), traffic simulation requires very simplified models from the geometric point of view, where a parametric bridge with the correct number of lanes can simplify the bridge:

- 2 lanes, before the inspection;

- 1 lane, after the inspection; and 
" 0 ", during the inspection when the bridge was temporary closed.

Then, it is important to define the type of road and other parameters, such as speed, number and type of vehicles, periods of the day (traffic in the early morning or late evening is different than traffic at midday), etc.

Information on road typology is mandatory also for the other roads in the considered area, since this information was not available in the cartographic layers. Adding stop signs, traffic lights, and other elements was a manual work carried out with the parametric modelling tools available in the BIM software.

Figure 10 shows some results of the simulation. Some roads around the area were completely remodeled because some elements were not correctly represented in the available GIS layers (especially roundabouts). The number of lanes, speed, and signs were manually defined in the software, starting from the existing vector layers projected on the DTM. The bridge was modeled with simplified elements and predefined shapes, without particular attention to the number of pillars or the actual form revealed by the laser scanner. Indeed, the model for a traffic simulation did not require this kind of information.

The simulation provided useful information about the intersections where cars accumulate during particular hours, as well as the traffic flow to leave the city, which changed with the closure of a lane.
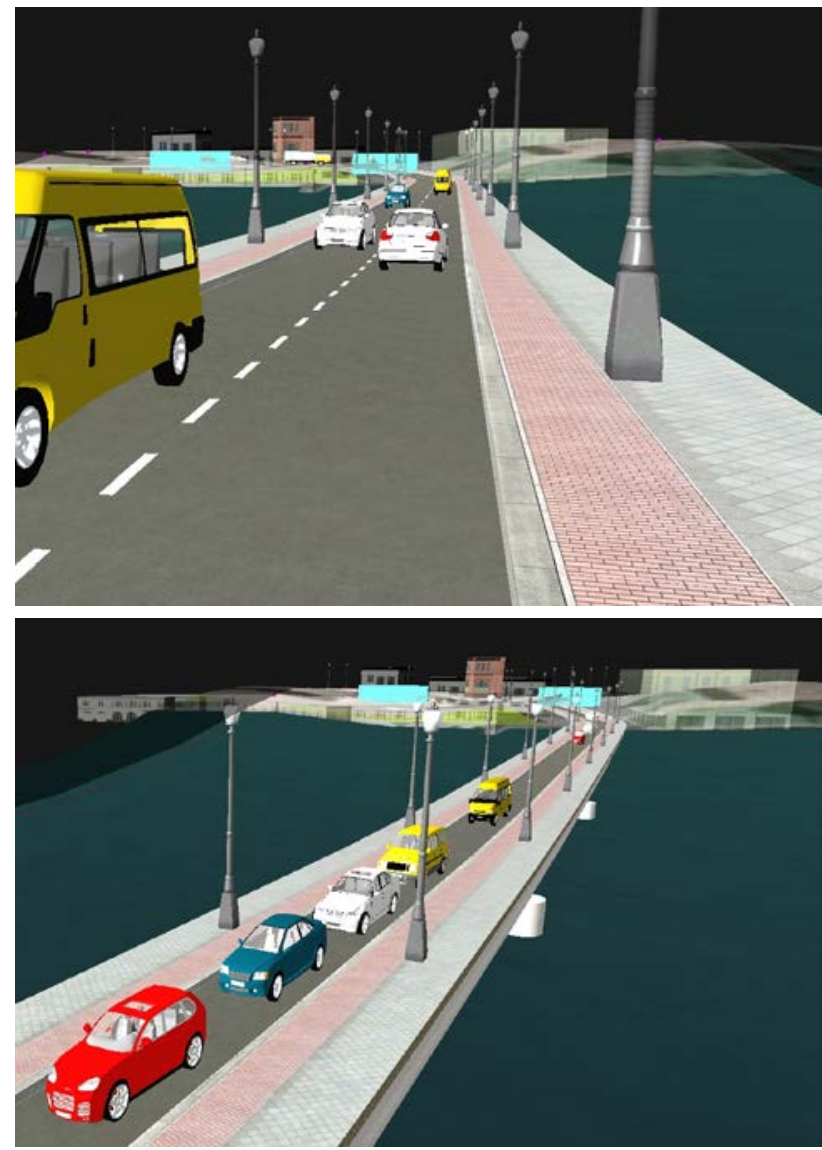

Figure 10. Some images of the simulation with 1 (bottom) and 2 lanes (top). The 3D model of the bridge is not the one generated from laser point clouds, as a detailed geometric model was not necessary for such traffic analysis. A simplified model of the bridge was generated via parametric modelling, changing in an automatic way the number of lanes.

\section{CONCLUSION}

Infrastructure BIM and geospatial data are intimately connected to design, build and manage existing or new infrastructures. Parametric modelling tools are able to generate objects that can interact not only with other objects, but also with geospatial data such as terrain models, orthophotos, or georeferenced vector files. If geometrically and semantically consistent models are generated, advanced simulations can be run to understand the impact of specific project choices.

This paper has illustrated and discussed some simulated and real examples to show similarities and differences between traditional BIM for buildings and infrastructures. Such work has revealed that building and infrastructure scales are correlated, but specific tools for data processing are required. In other words, transition from and to different commercial software is still mandatory, not only in a unique direction. For what concerns advanced geospatial analysis, GIS engines have much more tools and functionalities than BIM software, which are instead focused on the use of geospatial information integrated to infrastructure requirements.

BIM for buildings, infrastructures and GIS are therefore complementary. The choice of a specific software package will always depend on the kind of work required, as well as the level of detail and the type of deliverables to be produced. Probably, a single software (e.g. BIM sw for buildings, BIM sw for infrastructures, and GIS sw) is not sufficient to complete all the steps. Defining the level of detail (in terms of 3D geometry and associated information) is a fundamental aspect, which is also based on the requirements of the project (Banfi, 2017). Future work will be carried out on understanding the level of details of BIM/GIS applications, for which no solution is available at the moment. Mixed reality will be also integrated in future work BIM/GIS bacause it has a strong connection to such applications (Osello, 2015). Finally, transition from different software able to perform specific tasks in still mandatory, and this (sometimes) requires extra-work to adapt existing vector layers and use parametric modelling tools.

\section{ACKNOWLEDGEMENTS}

This work has been supported by the GAMHer project: Geomatics Data Acquisition and Management for Landscape and Built Heritage in a European Perspective, PRIN: Progetti di Ricerca di Rilevante Interesse Nazionale - Bando 2015, Prot. 2015HJLS7E.

\section{REFERENCES}

Amirebrahimi, S., Rajabifard, A., Mendis, P., Ngo, T., 2016. A BIM-GIS integration method in support of the assessment and $3 \mathrm{D}$ visualisation of flood damage to a building, Journal of Spatial Science, 61 (2), pp. 317-350.

F. Banfi, 2017. BIM orientation : grades of generation and information for different type of analysis and management process - The International Archives of the Photogrammetry, Remote Sensing and Spatial Information Sciences, Volume XLII-2/W5, 2017 26th International CIPA Symposium 2017, 28 August-01 September 2017, Ottawa, Canada.

Banfi, F., Barazzetti, L., Previtali, M., Roncoroni, F., 2017. Historic BIM: a new repository for structural health monitoring. 
The International Archives of the Photogrammetry, Remote Sensing and Spatial Information Sciences, Volume XLII-5/W1, 2017, 22-24 May 2017, Florence, Italy, 6 pages.

Barazzetti, L., Banfi, F., Brumana, R., Previtali, M., Roncoroni F., 2016. BIM from laser scans... not just for buildings: NURBS-based parametric modeling of a medieval bridge. ISPRS Ann. Photogramm. Remote Sens. Spatial Inf. Sci., III-5, pp. 51-56.

Baik, A., Yaagoubi, R., Boehm, J., 2015. Integration of Jeddah historical BIM and 3D GIS for documentation and restoration of historical monument. International Archives of the Photogrammetry, Remote Sensing and Spatial Information Sciences - ISPRS Archives, 40 (5W7), pp. 29-34

Borrmann, A., Kolbe, T.H., Donaubauer, A., Steuer, H., Jubierre, J.R., Flurl, M., 2014. Multi-scale geometric-semantic modeling of shield tunnels for GIS and BIM applications. Computer-Aided Civil and Infrastructure Engineering. Article in Press.

Bradley, A., Haijiang Li, Robert Lark, Simon Dunn, 2016. BIM for infrastructure: An overall review and constructor perspective, In Automation in Construction, Volume 71, Part 2 , 2016, Pages 139-152,

Cheng, J.C.P., Lu, Q., Deng, Y., 2016. Analytical review and evaluation of civil information modeling, Automation in Construction 67, 31-47, (ISSN: 0926-5805).

Chong, H.Y., Lopez, R., Wang, J., Wang, X., Zhao, Z., 2016. Comparative Analysis on the Adoption and Use of BIM in Road Infrastructure Projects. Journal of Management in Engineering, 32 (6), art. no. 05016021.

Del Giudice, M., Osello, A., Patti, E., 2015. BIM and GIS for district modeling. eWork and eBusiness in Architecture, Engineering and Construction - Proceedings of the 10th European Conference on Product and Process Modelling, ECPPM 2014, pp. 851-854.

Di Giulio, R., Turillazzi, B., Marzi, L., Pitzianti, S., 2017. Integrated BIM-GIS based design for high energy efficiency hospital buildings [Sistemi integrati BIM-GIS nella progettazione di edilizia ospedaliera ad alta efficienza energetica], (2017) TECHNE, 13, pp. 243-255.

Dongmo-Engeland, B., Merschbrock, C., 2017. A research review on building information modelling in infrastructure projects. Life-Cycle of Engineering Systems: Emphasis on Sustainable Civil Infrastructure - 5th International Symposium on Life-Cycle Engineering, IALCCE 2016, pp. 601-607.

Eastman, C., Teicholz, P., Sacks, R., Liston, K., 2011. BIM Handbook: A Guide to Building Information Modeling for Owners, Managers, Designers, Engineers and Contractors, 2 edition. John Wiley \& Sons Inc, 626 pages.

Ehrbar, H., 2016. Building Information Modelling - A new tool for the successful implementation of major projects of German railways [Building Information Modelling - Ein neues Werkzeug zur erfolgreichen Realisierung von Großprojekten der Deutschen Bahn]. Geomechanik und Tunnelbau, 9 (6), pp. 659-673.
El Meouche, R., Rezoug, M., Hijazi, I., 2013. Integrating and managing BIM in gis, software review. International Archives of the Photogrammetry, Remote Sensing and Spatial Information Sciences - ISPRS Archives, XL-2/W2, pp. 31-34.

Fan, D.-K., 2016. Research on the fusion technology of BIM and GIS applied in railway information deployment. Journal of Railway Engineering Society, 33 (10), pp. 106-110.

Fanning, B., Clevenger, C.M., Ozbek, M.E., Mahmoud, H., 2015. Implementing BIM on infrastructure: Comparison of two bridge construction projects, Practice Periodical on Structural Design and Construction, 20 (4), art. no. 04014044.

Kang, T.W., Hong, C.H., 2015. A study on software architecture for effective BIM/GIS-based facility management data integration. Automation in Construction, 54, art. no. 1887, pp. 25-38.

Karan, E.P., Irizarry, J., 2015. Extending BIM interoperability to preconstruction operations using geospatial analyses and semantic web services. Automation in Construction, 53, pp. 112.

Kim, J.-U., Kim, Y.-J., Ok, H., Yang, S.-H., 2016. A study on the status of infrastructure BIM and BIM library development. Proceedings - 2015 International Conference on Computational Science and Computational Intelligence, CSCI 2015, art. no. 7424220, pp. 857-858.

Kim, R., Park, S., Lee, H., 2015. The application evaluation of Autodesk storm and sanitary analysis for the low impact development design in the park area. International Journal of Multimedia and Ubiquitous Engineering, 10 (10), pp. 167-176.

Kim, S., Kim, J., Jung, J., Heo, J., 2015. Development of a 3d underground cadastral system with indoor mapping for As-Built BIM: The case study of gangnam subway station in Korea. Sensors (Switzerland), 15 (12), pp. 30870-30893.

König, M., Rahm, T., Nagel, F., Speier, L., 2017. Building Information Modeling in tunneling - digital design and construction of tunneling projects. [BIM-Anwendungen im Tunnelbau: Digitale Planung und Ausführung von Tunnelbauprojekten], Bautechnik, 94 (4), pp. 227-231.

Kortstee, E., van der Geest, L., 2017. BIM in the 'new international airport in Mexico City' project. Life-Cycle of Engineering Systems: Emphasis on Sustainable Civil Infrastructure - 5th International Symposium on Life-Cycle Engineering, IALCCE 2016, pp. 675-680.

Liu, X., Wang, X., Wright, G., Cheng, J.C.P., Li, X., Liu, R., 2017. A state-of-the-art review on the integration of Building Information Modeling (BIM) and Geographic Information System (GIS). ISPRS International Journal of Geo-Information, $6(2)$.

Minagawa, M., Kusayanagi, S., 2015. Study on BIM utilization for design improvement of infrastructure project. Procedia Engineering, 125, pp. 431-437.

Omoregie, A., Turnbull, D.E., 2016. Highway infrastructure and building information modelling in UK. Proceedings of the Institution of Civil Engineers: Municipal Engineer, 169 (4), art. no. 1500020 , pp. 220-232. 
Osello, A., 2015. Building Information Modelling - Geographic Information System - Augmented Reality per il Facility Management. Flaccovio Dario Editor, ISBN-10: 8857904784, ISBN-13: 978-8857904788, 297 pages.

Shou, W., Wang, J., Wang, X., Chong, H.Y., 2015. A Comparative Review of Building Information Modelling Implementation in Building and Infrastructure Industries, Archives of Computational Methods in Engineering, 22 (2), pp. 291-308.

Yamamura, S., Fan, L., Suzuki, Y., 2017. Assessment of Urban Energy Performance through Integration of BIM and GIS for Smart City Planning, Procedia Engineering, 180, pp. 14621472.

Vilgertshofer, S., Amann, J., Willenborg, B., Borrmann, A., Kolbe, T.H., 2017. Linking BIM and GIS models in infrastructure by example of IFC and CityGML. Congress on Computing in Civil Engineering, Proceedings, pp. 133-140.

Wang, Q.K., Li, P., Xiao, Y.P., Liu, Z.G., 2014. Integration of GIS and BIM in metro construction. Applied Mechanics and Materials, 608-609, pp. 698-702.

Wu, W., Yang, X., Fan, Q., 2014. GIS-BIM based virtual facility energy assessment (VFEA) - Framework development and use case of California State University, Fresno. Computing in Civil and Building Engineering - Proceedings of the 2014 International Conference on Computing in Civil and Building Engineering, pp. 339-346.

Zlatanova, S., Isikdag, U., 2016. The need to integrate BIM and geoinformation. GIM International, 30 (10), pp. 27-29 